Research Article

\title{
A study to assess and increase awareness regarding fixed dose combinations among medical undergraduates at Indore and Sagar, Madhya Pradesh, India
}

\author{
Shubham Atal ${ }^{1}$, Pradeep Phadnis ${ }^{2 *}$, Gopal Gudsurkar ${ }^{1}$
}

\begin{abstract}
${ }^{1}$ Department of Pharmacology, M.G.M. Medical College, Indore, MP, India,

${ }^{2}$ Department of Pharmacology, Bundelkhand Medical College, Sagar, MP, India
\end{abstract}

Received: 11 March 2016 Accepted: 15 March 2016

*Correspondence to:

Dr. Pradeep Phadnis,

Email: drpkphadnis@gmail.com

Copyright: (C) the author(s), publisher and licensee Medip Academy. This is an openaccess article distributed under the terms of the Creative Commons Attribution NonCommercial License, which permits unrestricted noncommercial use, distribution, and reproduction in any medium, provided the original work is properly cited.

\begin{abstract}
Background: Fixed dose combination (FDC) is a formulation containing two or more active ingredients in a fixed ratio of doses. Presently, there is lot of debate over rationality- irrationality, advantages-disadvantages of FDCs. Their judicious use or misuse is primarily up to the physician. FDCs should be focused upon in detail in undergraduate teaching as these students would be the future practitioners. Hence, the present study was undertaken to address these issue regarding FDCs in medical undergraduates in 2 government medical colleges in central India.

Methods: Questionnaire addressing various aspects of FDCs was prepared. Survey was conducted at medical colleges at Indore and Sagar among MBBS students belonging to $2^{\text {nd }}$ and $3^{\text {rd }}$ professional years. After pre-test questionnaires were filled, an educational intervention was given to students in the form of an interactive presentation on FDCs addressing all the major aspects. After a week, the post-test questionnaire containing same 20 questions was administered to the students. Data from pre and post-test responses was compiled in tabular form and analysed using simple percentage method.

Results: Pre-test responses showed that students already have a high level of awareness regarding basic concepts of FDCs; however they were found lacking in knowledge about the scientific aspects of FDCs. The educational interventional led to a substantial improvement in awareness regarding all aspects of FDCs and cleared students' confusions.

Conclusions: Students' awareness and knowledge about an important topic like FDCs should be strengthened through focused training which can prove critical in promoting rational use of drugs in the future.
\end{abstract}

Keywords: Fixed dose combinations, Awareness, Medical students, Questionnaire

\section{INTRODUCTION}

Fixed dose combination (FDC) is a combination of two or more active ingredients in a fixed ratio of doses. It may be administered as single entity products given along with or as a finished pharmaceutical product. ${ }^{1}$ Fixed dose combination products are acceptable when the combination has a proven advantage over single compounds administered separately in therapeutic effect, safety or compliance.

More than one-third of all the new drug products introduced worldwide during the last decade were fixed dose combination (FDCs) preparations. ${ }^{2}$ Fixed Dose
Combinations (FDCs) are seen to improve medication compliance by decreasing the pill burden of patients. Pill burden is not only the number of pills needing to be taken, but also the associated burdens such as keeping track of several medications, understanding their various instructions, etc.

It is an accepted fact that an FDC can be treated as a new drug, because by combining two or more drugs, the safety, efficacy, and bioavailability of the individual Active Pharmaceutical Ingredient (API) may change. As per the Drugs and Cosmetic Act, 1940, any new drug and the permission to market a drug is to be given by the Drugs Controller General of India (DCGI). 
Presently, there is lot of debate over rationality and irrationality of FDCs. As, there are two sides of each coin FDCs do also have advantages and disadvantages. It is up to the stakeholder to misuse it or use it judiciously by maintaining the balance. The rationality of FDCs should be based on certain aspects such as the drugs in the combination should act by different mechanisms, the pharmacokinetics must not be widely different, or the combination should not have supra additive toxicity of the ingredients. ${ }^{3}$

The reasons for misuse are: most commercial approach of industry, casual approach of all the stakeholders of health care regarding the rational drug therapy. Also, there is lack of awareness and orientation among patient, pharmacist and physician. ${ }^{4-7}$ CIMS list more hundreds of irrational drug combinations which are not approved in any developed country but are being marketed in India. All these facts need to be taught well to undergraduate medical students who are the budding clinicians of tomorrow so that they will be aware in future to judiciously prescribe drug therapy in common conditions like diabetes, hypertension, asthma, common infectious conditions, psychiatric illnesses and presence of multiple co morbidities where many medicines may be required by patients on a daily basis.

It is already well documented that medical and pharmacy undergraduate curriculum should also include rational use of FDCs and implementation of good ethical practices for use of FDCs. ${ }^{7}$ The present study was conducted to assess $\&$ evaluate the awareness about the usage of FDCs in medical undergraduates belonging to $2^{\text {nd }}$ and $3^{\text {rd }}$ professional years at M.G.M. Medical College, Indore and Bundelkhand Medical College, Sagar, as these students would be the future prescribing doctors. Furthermore, a focused educational intervention was planned to increase the level of awareness and knowledge of students regarding FDCs.

\section{METHODS}

\section{Type of study}

This is a questionnaire based study which was carried out in M.G.M. Medical College Indore and Bundelkhand Medical College, Sagar.

\section{Study population}

Total 340 medical undergraduates belonging to $2^{\text {nd }}$ and $3^{\text {rd }}$ professional years were selected for the study.

\section{Study procedure}

Literature survey was carried out to design questionnaire for the study on FDCs. Questionnaire containing questions addressing various aspects of FDCs was prepared. Questionnaire was finalized after conducting a pilot study on 10 students.

Study was conducted at M.G.M. Medical College, Indore and Bundelkhand Medical College, Sagar. These 2 study sites provide varied student populations; one being in a completely urban city and the other in a semi urban place. Study was conducted from November 2015 to December 2015 among $340 \mathrm{MBBS}$ students belonging to $2^{\text {nd }}$ and $3^{\text {rd }}$ professional years. These students were expected to have had an adequate exposure to pharmacology as a subject.

Pre-test questionnaires containing 20 different questions were provided to the students during randomly selected lectures, with due permission from concerned departments, in different batches. Personal details were not asked for any personal details to avoid inhibition at end of students in answering questions and to maintain confidentiality. Students were asked to voluntarily participate in the study and those unwilling to participate were asked to simply return the questionnaires unanswered. After pre-test questionnaires were filled, an educational intervention was given to students in the form of an interactive lecture delivered by the study authors with the help of a PowerPoint presentation on FDCs, addressing all the major aspects related to FDCs including various examples from clinical practice and literature review.

After a week of this intervention, the post-test questionnaires containing same 20 questions were administered to the same class of students and all those who have participated in the study and present in the class on the particular day were asked to fill out the questionnaire. The gap of one week was given to ensure that the increase in awareness and/or knowledge of students would not be purely due to immediate recall or short term memory. The data from pre and post-test responses was compiled in tabular form and analysed using simple percentage method. Percentage increase in awareness in the post test compared to pre-test was calculated for each question.

\section{RESULTS}

The analysis of responses obtained in the pre-test questionnaires (Table 1), for assessing the baseline awareness of students about FDCs, showed that the students had a high level of awareness (>75\%) regarding some of the basic aspects related to FDCs like knowing the term, constitution of FDC, their common use in prescriptions, providing benefits to patients by improving convenience/compliance and importance of the criteria of enhancement of therapeutic effect. 
Table 1: Assessment of (baseline) awareness of medical undergraduates regarding FDCs.

\begin{tabular}{|c|c|c|c|c|c|c|c|}
\hline \multirow{3}{*}{$\begin{array}{l}\text { Q. } \\
\text { No } \\
1\end{array}$} & \multirow{3}{*}{$\begin{array}{l}\text { Questions } \\
\text { Have you heard the term FDC? }\end{array}$} & \multicolumn{2}{|c|}{ Yes } & \multicolumn{2}{|l|}{ NO } & \multicolumn{2}{|c|}{ Don't know } \\
\hline & & \multicolumn{2}{|c|}{ Number \% } & \multicolumn{2}{|c|}{ Number \% } & \multicolumn{2}{|c|}{ Number \% } \\
\hline & & 300 & 88.23 & 30 & 8.8 & 10 & 2.9 \\
\hline 2 & FDC means fixed drug combination? & 164 & 48.23 & 154 & 45.29 & 22 & 6.4 \\
\hline 3 & FDC means fixed dose combination? & 208 & 61.17 & 112 & 32.9 & 20 & 5.88 \\
\hline 4 & $\begin{array}{l}\text { FDC contains two or more active ingredients in fixed proportion } \\
\text { of doses in a single formulation? }\end{array}$ & 288 & 84.70 & 20 & 5.88 & 32 & 9.4 \\
\hline 5 & FDCs are commonly prescribed by physicians? & 256 & 75.29 & 56 & 16.47 & 28 & 8.23 \\
\hline 6 & FDCs can provide therapeutic benefit to patients? & 258 & 90.58 & 06 & 1.76 & 26 & 7.64 \\
\hline 7 & $\begin{array}{l}\text { An important criterion for choosing drugs to be combined } \\
\text { together is similarity in pharmacokinetics? }\end{array}$ & 164 & 48.23 & 108 & 31.76 & 68 & 20 \\
\hline 8 & $\begin{array}{l}\text { An important criterion for choosing drugs to be combined is } \\
\text { enhanced therapeutic effect- potentiation, additive effect or } \\
\text { synergism? }\end{array}$ & 258 & 75.88 & 40 & 11.76 & 42 & 12.35 \\
\hline 9 & $\begin{array}{l}\text { Most important benefit from FDCs is patient convenience and } \\
\text { improved compliance? }\end{array}$ & 264 & 77.64 & 36 & 10.58 & 40 & 11.76 \\
\hline 10 & FDCs can help reduce cumulative toxicity? & 196 & 57.64 & 72 & 21.17 & 72 & 21.17 \\
\hline 11 & FDCs may reduce the cost of treatment? & 230 & 67.64 & 56 & 16.47 & 54 & 15.88 \\
\hline 12 & FDCs may result in enhanced adverse effects? & 116 & 34.11 & 152 & 44.70 & 72 & 21.17 \\
\hline 13 & FDCs may result in increased cost of treatment? & 74 & 21.76 & 186 & 54.70 & 80 & 23.52 \\
\hline 14 & All FDCs available in market are rational combinations? & 106 & 31.17 & 112 & 32.94 & 122 & 35.88 \\
\hline 15 & $\begin{array}{l}\text { All FDCs available in market are approved by drug regulatory } \\
\text { authority? }\end{array}$ & 218 & 64.11 & 50 & 14.70 & 72 & 21.17 \\
\hline 16 & $\begin{array}{l}\text { Disadvantage of FDCs is difficulty in dose adjustment or } \\
\text { flexibility in dosing? }\end{array}$ & 210 & 61.76 & 64 & 18.82 & 66 & 19.41 \\
\hline 17 & $\begin{array}{l}\text { Disadvantage of FDC may be use of sub therapeutic doses of } \\
\text { individual drugs? }\end{array}$ & 142 & 41.76 & 80 & 23.52 & 118 & 34.70 \\
\hline 18 & $\begin{array}{l}\text { A separate clinical trial is required for launching a new FDC } \\
\text { even if individual drugs are already approved? }\end{array}$ & 244 & 71.76 & 48 & 14.12 & 48 & 14.12 \\
\hline 19 & $\begin{array}{l}\text { Does any FDC feature in the National List of Essential } \\
\text { Medicines (NLEM) of India? }\end{array}$ & 14 & 4.11 & 20 & 5.88 & 306 & 90 \\
\hline 20 & Are there any FDCs which are banned in India? Give name/s & 10 & 2.94 & 12 & 3.52 & 318 & 93.52 \\
\hline
\end{tabular}

However, students weren't as well informed or aware regarding the more detailed scientific aspects related to FDCs like need for similarity in pharmacokinetics of ingredient drugs, rationality/approval status of FDCs available in market, disadvantages of FDCs and regulatory aspects. Similarly, students also seemed confused about the potential of FDCs to reduce as well as enhance toxicity (depending on particular combination) or their variable effect on cost of treatment; equivocal responses were obtained and number of students also expressed their lack of knowledge through the 'don't know' response.

Students had minimal awareness $(<5 \%)$ about any FDCs being available in India's National List of Essential Medicines (NLEM) or about FDCs being banned in the country.

The responses obtained on the same questionnaire after the educational intervention (post-test) indicated that the awareness of students was substantially improved regarding the scientific aspects of FDCs ranging from $35 \%$ - 356\% (Table 2); marginal improvement was seen in even those basic concepts where the awareness was already high. A strong majority of students of students $(77.64 \%)$ were able to recognize that there are indeed some approved FDCs in our NLEM and also that some FDCs are banned in India $(65.88 \%)$. Lot of students was able to provide names of 2-3 banned FDCs as well.

\section{DISCUSSION}

From the result it is evident that students are aware of the basic concept of fixed dose combination (FDC) but lack the knowledge regarding the deeper scientific aspects of the FDCs like their advantages, disadvantages, rationality, criteria to choose the drugs for a FDC, FDC listed in NLEM etc. 
Table 2: (Post-test) Increase in awareness of medical undergraduates regarding FDCs after educational intervention.

\begin{tabular}{|c|c|c|c|c|c|c|c|c|}
\hline \multirow{2}{*}{$\begin{array}{l}\text { Q. } \\
\text { No. }\end{array}$} & \multirow{2}{*}{ Questions } & \multirow{2}{*}{$\begin{array}{l}\text { Yes } \\
\text { No. }\end{array}$} & \multirow[b]{2}{*}{$\%$} & \multirow{2}{*}{$\begin{array}{l}\text { No } \\
\text { No. }\end{array}$} & \multirow[b]{2}{*}{$\%$} & \multicolumn{2}{|c|}{ Don't know } & \multirow{2}{*}{$\begin{array}{l}\% \text { Increase in } \\
\text { awareness }\end{array}$} \\
\hline & & & & & & No. & $\%$ & \\
\hline 1 & Have you heard the term FDC? & 340 & 100 & - & - & - & - & 20 \\
\hline 2 & FDC means fixed drug combination? & 54 & 15.88 & 284 & 83.52 & 24 & 7 & 84.4 \\
\hline 3 & FDC means fixed dose combination? & 282 & 82.94 & 34 & 10 & 24 & 7 & 35.59 \\
\hline 4 & $\begin{array}{l}\text { FDC contains two or more active } \\
\text { ingredients in fixed proportion of doses } \\
\text { in a single formulation? }\end{array}$ & 326 & 95.88 & 10 & 2.94 & 04 & 1.17 & 13.2 \\
\hline 5 & $\begin{array}{l}\text { FDCs are commonly prescribed by } \\
\text { physicians? }\end{array}$ & 296 & 87 & 42 & 12.35 & 2 & 5.88 & 15.55 \\
\hline 6 & $\begin{array}{l}\text { FDCs can provide therapeutic benefit to } \\
\text { patients? }\end{array}$ & 330 & 97 & 6 & 1.76 & 4 & 1.17 & 7 \\
\hline 7 & $\begin{array}{l}\text { An important criterion for choosing } \\
\text { drugs to be combined together is } \\
\text { similarity in pharmacokinetics? }\end{array}$ & 290 & 85.29 & 34 & 10 & 16 & 4.70 & 76.86 \\
\hline 8 & $\begin{array}{l}\text { An important criterion for choosing } \\
\text { drugs to be combined is enhanced } \\
\text { therapeutic effect-potentiation, additive } \\
\text { effect or synergism? }\end{array}$ & 324 & 95.29 & 10 & 2.94 & 6 & 1.76 & 25.58 \\
\hline 9 & $\begin{array}{l}\text { Most important benefit from FDCs is } \\
\text { patient convenience and improved } \\
\text { compliance? }\end{array}$ & 310 & 91.17 & 16 & 4.70 & 14 & 4.11 & 17.43 \\
\hline 10 & $\begin{array}{l}\text { FDCs can help reduce cumulative } \\
\text { toxicity? }\end{array}$ & 284 & 83.52 & 26 & 7.64 & 30 & 8.82 & 44.9 \\
\hline 11 & FDCs may reduce the cost of treatment? & 298 & 87.64 & 32 & 9.41 & 10 & 2.94 & 29.57 \\
\hline 12 & $\begin{array}{l}\text { FDCs may result in enhanced adverse } \\
\text { effects? }\end{array}$ & 274 & 80.58 & 40 & 11.76 & 26 & 7.64 & 136.24 \\
\hline 13 & $\begin{array}{l}\text { FDCs may result in increased cost of } \\
\text { treatment? }\end{array}$ & 260 & 76.47 & 52 & 15.29 & 28 & 8.23 & 251.42 \\
\hline 14 & $\begin{array}{l}\text { All FDCs available in market are } \\
\text { rational combinations? }\end{array}$ & 86 & 25.29 & 214 & 62.94 & 40 & 11.76 & 91.07 \\
\hline 15 & $\begin{array}{l}\text { All FDCs available in market are } \\
\text { approved by drug regulatory authority? }\end{array}$ & 88 & 25.88 & 228 & 67.05 & 24 & 7.05 & 356.12 \\
\hline 16 & $\begin{array}{l}\text { Disadvantage of FDCs is difficulty in } \\
\text { dose adjustment or flexibility in dosing? }\end{array}$ & 282 & 82.94 & 34 & 10 & 24 & 7 & 34.29 \\
\hline 17 & $\begin{array}{l}\text { Disadvantage of FDC may be use of } \\
\text { subtherapeutic doses of individual } \\
\text { drugs? }\end{array}$ & 246 & 72.35 & 44 & 12.94 & 50 & 14.70 & 73.25 \\
\hline 18 & $\begin{array}{l}\text { A separate clinical trial is required for } \\
\text { launching a new FDC even if individual } \\
\text { drugs are already approved? }\end{array}$ & 122 & 35.88 & 200 & 58.82 & 18 & 5.29 & 316.57 \\
\hline 19 & $\begin{array}{l}\text { Does any FDC feature in the National } \\
\text { List of Essential Medicines (NLEM) of } \\
\text { India? }\end{array}$ & 264 & 77.64 & 10 & 2.94 & 64 & 18.84 & 454.57 \\
\hline 20 & $\begin{array}{l}\text { Are there any FDCs which are banned } \\
\text { in India? Give name/s }\end{array}$ & 224 & 65.88 & 10 & 2.94 & 106 & 31.17 & 558.8 \\
\hline
\end{tabular}

By giving a focused educational intervention through an interactive classroom presentation, the awareness of students was substantially increased about all aspects of FDCs. Understanding this concept of rationality of FDCs is most important factor while prescribing it. As the students are budding physicians it is most important for them to understand this because not all FDCs in Indian market are rational combinations. Rational use of medicines in therapeutics is a much bigger challenge than ever before. Rational use of medicine means use of a right medicine, in the right manner, at right time, in the 
right type of patients, at a right cost i.e. "the rule of right".

Also students became more aware about the disadvantages of FDCs like difficulty in dose adjustment and use of subtherapeutic dose of individual drugs in FDC. Most of the students were unaware of any FDC listed in NLEM but majority could even name some FDCs in National list of essential medicine (NLEM) and those which are banned in India.

Overall the students became more aware about all the various aspects of FDCs and their importance and their use in clinical practice. The development of fixed-dose combinations (FDCs) is becoming increasingly important in clinical pharmacology. FDCs products are often claimed to make medicine-taking more convenient for patients taking multiple medication with the potential of improving compliance.

FDCs should only be used if there is clear therapeutic objective justifying its use, when patient needs all components of a FDC and when combination is proven to be better than single drug for that combination. Such combinations of drugs are being used in the treatment of a wide range of conditions and a useful in the management of HIV/AIDS, malaria and Tuberculosis. ${ }^{9}$

\section{Advantages and disadvantages of the FDCs}

Use of FDCs is associated with many advantages like synergistic action and increased efficacy (e.g. cotrimoxazole, antihypertensives), reduced adverse effects (e.g. levodopa with carbidopa, thiazides with potassium sparing diuretics), reduced pill burden and cost of therapy (not always) and better patient compliance and convenience to patients (e.g. anti-tubercular drug combinations). ${ }^{10}$

However, certain disadvantages like incompatible pharmacokinetics, inflexible dose ratio, increased toxicity and cost, use of subtherapeutic dose of individual drugs, contraindication of one component of the FDC decreased their utility.

\section{Rationality of FDCs}

There are no uniform worldwide acceptable criteria or uniform principles to judge rationality of FDCs. Rationality criteria to analyse FDCs can be identified from available literature: ${ }^{10-14}$

- There is a medical rationale for combining the active components.

- Combination should have advantage of established evidence of efficacy and safety over single compounds administered separately.

- Overall cost of the combination should preferably be less than the combined cost of the individual components.
- Dose and proportion of each API present in FDC should be appropriate for its intended use.

- The pharmacokinetic (PK) properties of individual drugs should be matching.

- Individual drugs should have different mechanism or/and site of action.

- For antimicrobials - reduces resistance.

- One drug acts as a booster for another.

- Therapy is simplified, particularly when the existing therapy is complex or onerous

The majority of these criteria are also recommended by WHO. ${ }^{14}$ Based on these criteria FDCs are classified in rational irrational and semi rational.

\section{Rational FDCs}

Those FDCs which met the above criteria are considered as rational. FDCs which matched exactly with those given in either EML of WHO or NLEM of India are considered rational. Mere convenience cannot be the justification for rationality of a FDC which is commonly observed in clinical practice. There are many FDCs which are rational but used irrationally in practice. For example in the treatment of diabetes, hypertension ideally monotherapy with single drug should be used. If there is no adequate response then only other drug should be added. So starting with FDCs even at lower dose strength would be irrational. ${ }^{15}$

\section{Semirational FDCs}

All those FDCs which do not match with FDCs listed in the WHO EML or NLEM of India but still demonstrate a synergistic or additive pharmacodynamic profile and at the same time do not have the potential to cause any increase in adverse effects can be considered semi rational, even though they do not strictly meet the pharmacokinetics or cost criteria. For example the combination of two antihypertensives (atenolol plus amlodipine, enalapril plus hydrochlorothiazide) or the combination of two diuretics (spironolectone plus frusemide) can be considered as semirational. In other words, they are not exactly rational but there is some justification for combining them. Eg: paracetamol with one antihistaminic, or antihistaminic with antitussive, caffeine with ergotamine and paracetamol.

\section{Irrational FDCs}

When a FDC is not found to serve any PD or PK advantage, or does not have additive or synergistic effect or is shown to have the potential of causing enhanced adverse effects, it is considered as irrational FDC irrespective of purported advantages of cost or compliance. Irrational FDCs are so much common in clinical practice. For eg: Norfloxacin/Ciproflxacin + Metronidazole/Tinidazole: useful only if there if mixed infection i.e. bacterial diarrhoea + amoebic dysentery, which is uncommon. Their dosing frequency also differs, 
and unnecessary use can give rise to resistance. Similarly, the NSAID combinations: No synergism/additive effect can be expected when two drugs acting on the same enzyme are combined; efficacy is unlikely to improve but adds to cost and adverse effect of GI irritation. ${ }^{16}$

\section{FDCs in global and Indian scenario}

Globally, FDCs are used extensively worldwide. $10 \%$ of new products in Japan are FDCs, about $56 \%$ of all drugs prescribed in European countries like Spain are FDCs, showing the higher trend of prescribing these formulations. ${ }^{17}$ The essential list of medicines by WHO in 2011 includes 358 medicines with only 24 FDCs. ${ }^{18}$ This shows an increased need of inclusion of FDCs in the essential list of medicines by standardizing and expediting the process of approval of FDCs worldwide.

As far as Indian scenario is concerned, with a population of 120 crore plus people, we have the 4th largest pharmaceutical industry. ${ }^{19}$ National list of Essential Medicines $\left(3^{\text {rd }}\right.$ list, 2011) of Government of India includes 348 essential drugs, including 16 FDCs only. ${ }^{20}$ There are more than 80,000 commercial formulations available either as single drug formulations or FDCs in Indian market and currently only 1193 FDC are approved by DCGI in India. ${ }^{21}$

India is the country with significant drug use problem. There is a concern regarding the irrational production, prescription, and use of FDCs. The rationality of a fixed dose combination is the one of the most burning issues in today's clinical practice. The Indian laws, till recently, were not properly defined to grant marketing approvals for the FDCs by state or central drug controlling authorities. Therefore, the state drug controlling authorities have continuously been approving various FDCs, lacking pharmacodynamics or pharmacokinetic advantages and acceptable rationale. ${ }^{15}$

This shows lack of strict regulations over FDCs in India by government. Parliamentary standing committee on health and family welfare observed that most of the FDCs in Indian market are launched without prior approval of CDSCO. ${ }^{22}$ This might be hazardous to the patients because of lack of safety and efficacy report of the combination. To regulate this, the Central Drugs Standards Control Organization, India has issued now policy guidelines for approval of FDCs in India.

\section{Regulatory guidelines for approval of FDCs in India: ${ }^{23}$}

Any new FDC prior launching in market needs approval by $\mathrm{CDSCO}$ and is classified in 4 categories.

\section{Category I}

One or more active pharmaceutical ingredient(s) of the FDC is a new drug. For such FDCs to be approved for manufacture/ import and marketing, the data required to be submitted will be the same as that for a new chemical entity (NCE) as per Schedule Y.

\section{Category II}

All active pharmaceutical ingredients are approved/marketed in India individually and the FDC is proposed for marketing, then a bio-equivalence study should be conducted proving the FDC \& the active APIs given concurrently are bioequivalent.

\section{Category III}

FDC is marketed in India but some changes are sought like change in the ratio of active pharmaceutical ingredients (provided single entity doses are approved) and the doses of the individual components are within the approved dose range for the individual drugs.

In this case also all conditions for category II have to be fulfilled along with the in vitro animal study data report of individual drug.

\section{Category IV}

Subsequent approvals after the approval of primary applicant's FDC falls in this catogory. FDCs which are of same strength/ratio, formulation and indication(s) of the already approved FDC of a primary applicant the various documents along with Regulatory status of the FDC including the details of various companies marketing the FDC, report of bio-equivalence study conducted proving the FDC \& the active APIs given concurrently are bioequivalent and complete chemical and pharmaceutical data including stability data have to be submitted.

Medical experts worldwide have expressed serious concerns over the increased marketing of drug combinations by pharmaceutical companies, particularly in the developing countries like India. ${ }^{24}$ From all the above mentioned facts, it is evident that there is increasing need of awareness about the concept of FDCs in medical students learning pharmacology as they are the future physicians.

\section{CONCLUSION}

To conclude, we would like to state that it is imperative that the concept of FDCs should be emphasized upon in sufficient detail, in our theory and practical academic curriculum for the medical students so that there will be fine grooming of these budding doctors not only regarding the FDCs but also drug-drug interactions, rationality of prescribing especially the multi-drug regimens in chronic diseases more precisely. It is the also need of the hour that hospitals should constitute drugs review committees to promote rational prescription of FDCs among the physicians in the hospital. 


\section{ACKNOWLEDGEMENTS}

The authors would like to acknowledge the faculty and staff of M.G.M. Medical College, Indore and Bundelkhand Medical College, Jabalpur for their support and cooperation during the conduct of this study.

Funding: No funding sources

Conflict of interest: None declared

Ethical approval: The study was approved by the Institutional Ethics Committee

\section{REFERENCES}

1. Sreedhar D, Subramanian G, Udupa N. Combination drugs: are they rational? Curr Sci. 2006:91:406.

2. Poudel A, Palaian S, Shankar PR, Jayasekera J, Izham MIM. Irrational fixed dose combinations in Nepal: Need for intervention. Kathmandu Univ Med J. 2008;23:399-405.

3. Amitava S. Indian market's fixation with fixed dose combinations. Rational Drug Bulletin. 2002;12:1.

4. Chakraborti A. Fixed dose combinations in therapy. Pharmavoice Express Pharma. 2007:1-15.

5. Gautam CS, Saha L. Fixed dose combination (FDCs): rational or irrational: a view point. British J Clin Pharmacol. 2007;65:795-6.

6. Sreedhar D, Janodia MD, Ligade VS, Mohapatra S, Ganguly R, Udupa N. Fixed dose combinations: rational or irrational?. Curr Sci. 2008;95:581-3.

7. Tandon VR. Is enalapril and losartan combination rational? Indian J Pharmacol. 2006;38:295-8.

8. Gautam CS, Aditya S. Irrational drug combination: need to sensitize undergraduates. Indian $\mathbf{J}$ Pharmacol. 2006;38:169-70.

9. Chandler SG, Lekha S. Fixed dose drug combinations (FDCs): rational or irrational: a view point. Br J Clin Pharmacol. 2008;65:795-6.

10. Shrivastava SK. Chapter 90 Fixed Dose Combinations: General comments and complete textbook of medical pharmacology. Sirmour, India: Avichal Pub Company. 2012;2:1413-4.

11. Desai SV. Essential drug and rational drug therapy. Bull Soc Rational Ther. 2001;12:2-7.

12. Patel S, Shah R, Desai S. A study of prevailing scenario of fixed-dose drug combinations (FDCs) available in Indian market. Int $J$ Pharm. 2015;5(4):1155-63.

13. Drugs banned in India. Available at: www.cdsco.nic.in/html/Drugsbanned.html. Accessed on 17 February, 2016.

14. WHO Technical Report Series, No. 929. Annex 5. Guidelines for registration of fixed-dose combination medicinal products. Geneva 2005. Available as pdf.
15. Shrivastava SK. A complete textbook of medical pharmacology. Sirmour, India: Avichal publishing company. 2012;1:58-59.

16. Chowta MN, Shenoy A, Kamath A. Manual of practical pharmacology for MBBS. 1st ed. Sirmour, India: Avichal publishing company. 2016:33-34.

17. Poudel A, Palaian S, Shankar PR, Jayasekera J, Izham MI. Irrational fixed dose combinations in Nepal: Need for intervention. Kathmandu Univ Med J. 2008;6:399-405.

18. World Health Organization (WHO) Model List of Essential Medicines for adults 17th list (updated), March 2011. Available at: http://www.who.int/medicines/publications/essential medicines/en/index.html. Accessed on 17 February, 2016.

19. Hindoliya M, Sharma PK, Dhaneria SP. Prescribing trends of fixed dose combinations in teaching and non-teaching hospitals of Ujjain District. J Pharm Res. 2012;5:3503-5.

20. National list of essential medicines. 2011. Available at:

http://www.whoindia.org/LinkFiles/Essential_Medic ine_List_Essential Medicine-2011.pdf. Accessed on 17 February, 2016.

21. Fixed Dose Combinations Approved By Dcg (I) Since 1961 Till November, 2014. Available at:http://cdsco.nic.in/writereaddata/Aprroved\%20FD C\%201ist\%20till\%20november\%202014.pdf Accessed on 05 February, 2016.

22. Department-related parliamentary standing committee on health and family welfare, 59th report on the functioning of the central drugs standard control organization (CDSCO). Available at: http://164.100.47.5/newcommittee/reports/englishco mmittees/committee \%20on\%20health\%20and\%20fa mily\%20welfare/59.pdf. Accessed on 07 February, 2016.

23. Policy guidelines for approval of fixed dose combinations (FDCs) in India. Central Drugs Standard Control Organization. Directorate general of health services. Ministry of Health \& Family Welfare. Govt. Of India. 2013. Pdf.

24. Pradeep DT, Purohit S. Rationality of fixed dose combinations: necessity to weed out the irrational combinations mushrooming in pharmaceutical industry. India; Pharmacinfo.net. Available at: http://www.pharmainfo.net/reviews/rationalityfixed-dose combinations necessity- weed-outirrational-combinations. Accessed on 17 February, 2016.

Cite this article as: Atal S, Phadnis P, Gudsurkar G. A study to assess and increase awareness regarding fixed dose combinations among medical undergraduates at Indore and Sagar, Madhya Pradesh, India. Int J Basic Clin Pharmacol 2016;5:300-6. 